Review Article

\title{
Genetic Polymorphism of Angiotensin-Converting Enzyme and Chronic Obstructive Pulmonary Disease Risk: An Updated Meta-Analysis
}

\author{
Sang Wook Kang, ${ }^{1}$ Su Kang Kim, ${ }^{2}$ Joo-Ho Chung, ${ }^{2}$ Hee-Jae Jung, \\ Kwan-Il Kim, ${ }^{3}$ Jinju Kim, ${ }^{4}$ and Ju Yeon Ban ${ }^{1}$ \\ ${ }^{1}$ Department of Dental Pharmacology, School of Dentistry, Dankook University, Cheonan 31116, Republic of Korea \\ ${ }^{2}$ Kohwang Medical Research Institute, School of Medicine, Kyung Hee University, Seoul 02447, Republic of Korea \\ ${ }^{3}$ Division of Allergy and Respiratory System, Department of Korean Internal Medicine, College of Korean Medicine, \\ Kyung Hee University, Seoul 02447, Republic of Korea \\ ${ }^{4}$ Department of Korean Physiology, College of Pharmacy, Kyung Hee University, Seoul 02447, Republic of Korea
}

Correspondence should be addressed to Ju Yeon Ban; jyban@dankook.ac.kr

Received 28 April 2016; Revised 13 September 2016; Accepted 19 September 2016

Academic Editor: Anastasia Kotanidou

\begin{abstract}
Copyright (C) 2016 Sang Wook Kang et al. This is an open access article distributed under the Creative Commons Attribution License, which permits unrestricted use, distribution, and reproduction in any medium, provided the original work is properly cited.

The relationship between polymorphism of the angiotensin I converting enzyme (ACE) gene and chronic obstructive pulmonary disease (COPD) has been examined in many previous studies. However, their results were controversial. Therefore, we performed a meta-analysis to evaluate the relationship between the ACE gene and the risk of COPD. Fourteen case-control studies were included in this meta-analysis. The pooled $p$ value, odds ratio (OR), and $95 \%$ confidence interval $(95 \% \mathrm{CI})$ were used to investigate the strength of the association. The meta-analysis was performed using comprehensive meta-analysis software. Our meta-analysis results revealed that ACE polymorphisms were not related to the risk of COPD ( $p>0.05$ in each model). In further analyses based on ethnicity, we observed an association between insertion/deletion polymorphism of the ACE gene and risk of COPD in the Asian population (codominant $2, \mathrm{OR}=3.126,95 \% \mathrm{CI}=1.919-5.093, p<0.001$; recessive, $\mathrm{OR}=3.326,95 \% \mathrm{CI}=2.190-5.050$, $p<0.001)$ but not in the Caucasian population $(p>0.05$ in each model). In conclusion, the present meta-analysis indicated that the insertion/deletion polymorphism of the ACE gene may be associated with susceptibility to COPD in the Asian population but not in the Caucasian population. However, the results of the present meta-analysis need to be confirmed in a larger sample.
\end{abstract}

\section{Introduction}

COPD is a serious disease which is characterized by destruction of the lung parenchyma and inflammation of the peripheral airways [1]. COPD is a global health problem due to its high prevalence, morbidity, mortality, and social care cost $[2,3]$. The Global Burden of Disease (GBD) study reported that COPD was the sixth leading cause of death in 1990 and the fourth leading cause of death in 2000 [4]. Also, an estimated 4.7 million people die due to COPD [5]. The cause of COPD is multifactorial. Cigarette smoking is known to be the major cause of COPD, but some COPD cases cannot be explained by smoking alone [6]. Environmental exposure such as occupational exposures [7] and indoor biomass fuel burning [8] is closely related to the development of COPD. In addition, many previous studies have reported the association between genetic factors and COPD susceptibility. Previous family and twin studies have shown the role of genetic factors in COPD susceptibility [9]. Recently, some authors have used genetic polymorphisms to explain the genetic contribution to the development of COPD, and several candidate genes such as proteinase-activated receptor-1 [10], plasminogen activator inhibitor-1 [11], and $\beta 2$-adrenergic receptor [12] were reported to have an association with COPD susceptibility.

ACE has been one of the most studied candidate genes [13-16] due to its wide role in the development of various 
diseases such as systemic lupus erythematosus [17], hypertension, chronic kidney disease [18], and diabetic nephropathy [19]. The ACE gene is located on the chromosome 17q23 and it encodes angiotensin-converting enzyme (ACE) which plays a role in converting angiotensin I into angiotensin II. One of the well-known polymorphisms in the ACE gene is the insertion/deletion polymorphism, which is $287 \mathrm{bp}$ long and results in three genotypes (II, ID, and DD). The genotypes have been shown to be associated with ACE activity and levels in plasma and tissues [20]. A previous study reported that ACE activity depends on the $\mathrm{O} 2$ concentration of the blood and increased ACE levels due to hypoxia could be associated with severe tissue damage [21]. In COPD patients, the ACE activity increased during exacerbation, while it decreased during remission [22]. Inhibition of ACE using an ACE inhibitor could improve the exercise capacity during pulmonary rehabilitation in COPD [23]. ACE has been known to have an association with COPD, and an ACE inhibitor has been used to treat COPD. Thus, many previous studies have attempted to clarify the association between $A C E$ polymorphism and COPD susceptibility, but several studies have reported conflicting results. Therefore, the aim of this meta-analysis was to investigate the possible association between ACE polymorphism and COPD risk based on all available relevant studies.

\section{Materials and Methods}

2.1. Search Strategy. All studies which were published from January 1, 1998, to March 1, 2016, and which examined the association between ACE insertion/deletion polymorphism and COPD risk were carefully searched. Case-control studies were searched in PubMed, Google, Embase, and Korean databases (KISS, KMbase, and RISS) up to March 2015. The following keywords were used: "angiotensin-converting enzyme" or "ACE” AND "polymorphisms" AND "chronic obstructive pulmonary disease or COPD." Only human studies were selected. Additional studies were identified by a manual search of the reference of the related original studies or review articles. If data or data subsets were published in more than one article, only the publication with the largest sample size was included.

2.2. Inclusion and Exclusion Criteria. The inclusion criteria were as follows: (1) the studies should have evaluated the relationship between the ACE insertion/deletion polymorphism and COPD risk; (2) the study design should be a case-control study; and (3) the authors should have provided sufficient data on genotype distributions in the COPD group and the control group to estimate the odds ratio (OR) with a 95\% confidence interval (CI). Studies were excluded if the genotype distribution in the control groups deviated from the Hardy-Weinberg equilibrium.

2.3. Data Extraction. Two investigators independently extracted data and created an analysis. When the investigators differed in their conclusions, they rechecked the data and reached a consensus through discussion. Data extracted from the selected articles included the first author's name, the year of publication, country of origin, ethnicity of the study population, the number of cases and controls, and the genotype frequency of $A C E$ insertion/deletion polymorphism.

2.4. Statistical Analysis. Meta-analysis was performed using a comprehensive meta-analysis software program (Biostat Corporation, NJ, USA). The pooled $p$ value, OR, and 95\% CI were used to investigate the association between the risk of COPD and $A C E$ insertion/deletion polymorphism. In the present meta-analysis, we adopted the following genetic models $[24,25]$ : codominant 1 (I/D genotype versus I/I genotype), codominant 2 (D/D genotype versus I/I genotype), dominant (D/D genotype + I/D genotype versus I/I genotype), and recessive (D/D genotype versus I/D genotype + I/I genotype) models and the allele model ( $\mathrm{D}$ allele versus I allele). For codominant 1 , codominant 2 , and dominant models, we used I/I genotype as the reference group. For the recessive model, I/D genotype $+\mathrm{I} / \mathrm{I}$ genotype was used as the reference group. Firstly, we assessed the heterogeneity among studies to select the analysis model. The $\chi^{2}$-test-based $Q$ statistic test and the $I^{2}$ test were applied. The random-effects MantelHaenszel method was adopted if the result of the $Q$ test was $p<0.05$ or the $I^{2}$ statistic was $>50 \%$, which indicated a statistically significant degree of heterogeneity among studies. Otherwise, the fixed-effects Mantel-Haenszel method was adopted. Publication bias was evaluated by Egger's regression. A $p$ value less than 0.05 was considered statistically significant.

\section{Results}

3.1. Characteristics of Eligible Studies. Table 1 describes the characteristics of selected studies included in the metaanalysis. Briefly, the meta-analysis in the present study was performed with fourteen articles [13-16, 26-35]. After pooling all data, these 14 articles included 977 patients with COPD and 1,092 control subjects.

3.2. Quantitative Synthesis. Among these 14 studies, two studies $[15,26]$ showed an error in the Hardy-Weinberg equilibrium in the control group $(p<0.001$ and $p=$ 0.004 , resp., Table 2). These two studies were excluded from the evaluation of the exact analysis. To conduct risk assessment in all COPD cases and control patients, we assessed the heterogeneity in each model, respectively (codominant, dominant, and recessive models and the allele model). The results of the heterogeneity test for meta-analysis are shown in Table 2. The random-effects method was applied if the result of the $Q$ test was $p<0.05$ or the $I^{2}$ statistic was $>50 \%$. Otherwise, the fixed-effects method was adopted. Insertion/ deletion polymorphism of the ACE gene did not show any significant association with susceptibility to COPD in each model, respectively ( $p>0.05$, Table 2$)$.

We performed a meta-analysis in two subgroups based on ethnicity: Asian population and Caucasian population. Results of the analysis in the Asian subgroup and the Caucasian subgroup are presented in Table 2 and Figure 1. For 
TABLE 1: Information of eligible studies included in the meta-analysis.

\begin{tabular}{|c|c|c|c|c|c|c|c|c|c|c|c|c|c|c|}
\hline \multirow{2}{*}{ Author } & \multirow{2}{*}{ Year } & \multirow{2}{*}{ Country } & \multirow{2}{*}{$\mathrm{COPD} /$ control } & \multicolumn{3}{|c|}{ COPD } & \multicolumn{3}{|c|}{ Control } & \multicolumn{2}{|c|}{ COPD } & \multicolumn{2}{|c|}{ Control } & \multirow{2}{*}{ HWE in control } \\
\hline & & & & $\mathrm{I} / \mathrm{I}$ & $\mathrm{I} / \mathrm{D}$ & $\mathrm{D} / \mathrm{D}$ & $\mathrm{I} / \mathrm{I}$ & $\mathrm{I} / \mathrm{D}$ & $\mathrm{D} / \mathrm{D}$ & I & $\mathrm{D}$ & I & $\mathrm{D}$ & \\
\hline Simsek & 2013 & Turkey & $66 / 40$ & 15 & 20 & 31 & 8 & 19 & 13 & 50 & 82 & 35 & 45 & 0.823 \\
\hline Ulasli & 2013 & Turkey & $80 / 49$ & 16 & 17 & 49 & 6 & 10 & 33 & 49 & 111 & 22 & 76 & 0.004 \\
\hline Ayada & 2014 & Turkey & $47 / 64$ & 8 & 26 & 13 & 8 & 28 & 28 & 42 & 52 & 44 & 84 & 0.808 \\
\hline Ahsan & 2004 & India & $27 / 66$ & 10 & 12 & 5 & 23 & 33 & 10 & 32 & 22 & 79 & 53 & 0.743 \\
\hline $\mathrm{Gu}$ & 2003 & China & $122 / 159$ & 28 & 37 & 57 & 49 & 85 & 25 & 93 & 151 & 183 & 135 & 0.235 \\
\hline Hopkinson & 2008 & UK & $103 / 101$ & 29 & 49 & 25 & 28 & 49 & 24 & 107 & 99 & 105 & 97 & 0.777 \\
\hline Jiang & 2004 & China & $30 / 30$ & 7 & 12 & 11 & 15 & 10 & 5 & 26 & 34 & 40 & 20 & 0.171 \\
\hline Pabst & 2009 & German & $152 / 158$ & 43 & 76 & 33 & 39 & 69 & 50 & 162 & 142 & 147 & 169 & 0.124 \\
\hline Tkáčová & 2005 & Slovakia & $66 / 118$ & 15 & 31 & 20 & 19 & 68 & 31 & 61 & 71 & 106 & 130 & 0.074 \\
\hline van Suylen & 1999 & Netherlands & $87 / 95$ & 17 & 43 & 27 & 17 & 50 & 28 & 77 & 97 & 84 & 106 & 0.514 \\
\hline Wang & 2000 & China & $20 / 38$ & 5 & 7 & 8 & 13 & 18 & 7 & 17 & 23 & 44 & 32 & 0.861 \\
\hline Yildiz & 2003 & Turkey & $42 / 40$ & 7 & 21 & 14 & 10 & 18 & 12 & 35 & 49 & 38 & 42 & 0.536 \\
\hline Zhang & 2008 & China & $61 / 57$ & 21 & 27 & 13 & 20 & 28 & 9 & 69 & 53 & 68 & 46 & 0.877 \\
\hline Busquets & 2007 & Spain & $74 / 77$ & 7 & 40 & 27 & 11 & 53 & 13 & 54 & 94 & 75 & 79 & $<0.001$ \\
\hline
\end{tabular}

COPD: chronic obstructive pulmonary disease; ACE: angiotensin-converting enzyme; I/I: insertion/insertion genotype; I/D: insertion/deletion genotype; D/D: deletion/deletion genotype; HWE: Hardy-Weinberg equilibrium.

TABLE 2: Overall analysis between ACE insertion/deletionpolymorphism and susceptibility to COPD.

\begin{tabular}{lcccccccc}
\hline \multirow{2}{*}{ Comparisons } & \multirow{2}{*}{ Population } & \multicolumn{2}{c}{ Heterogeneity } & \multirow{2}{*}{ Model } & OR & 95\% CI & Egger' $p$ \\
\hline \multirow{3}{*}{ D/D versus I/I } & All & 0.005 & 58.855 & Random & 1.299 & $0.840-2.010$ & 0.240 & 0.612 \\
& Asian & 0.358 & 6.964 & Fixed & 3.126 & $1.919-5.093$ & $<\mathbf{0 . 0 0 1}$ & 0.740 \\
& Caucasian & 0.731 & $<0.001$ & Fixed & 0.852 & $0.619-1.172$ & 0.325 & 0.209 \\
& All & 0.846 & $<0.001$ & Fixed & 0.904 & $0.714-1.145$ & 0.404 & 0.368 \\
I/D versus I/I & Asian & 0.384 & 1.692 & Fixed & 0.956 & $0.624-1.466$ & 0.838 & 0.249 \\
& Caucasian & 0.862 & $<0.001$ & Fixed & 0.882 & $0.664-1.172$ & 0.386 & 0.800 \\
& All & 0.001 & 66.564 & Random & 1.167 & $0.915-1.489$ & 0.213 & 0.511 \\
D versus I & Asian & 0.156 & 42.596 & Fixed & 1.887 & $1.468-2.427$ & $<\mathbf{0 . 0 0 1}$ & 0.861 \\
& Caucasian & 0.574 & $<0.001$ & Fixed & 0.926 & $0.790-1.086$ & 0.347 & 0.222 \\
& All & 0.509 & $<0.001$ & Fixed & 1.040 & $0.835-1.295$ & 0.728 & 0.451 \\
D/D + I/D versus I/I & Asian & 0.412 & $<0.001$ & Fixed & 1.500 & $1.018-2.210$ & $\mathbf{0 . 0 4 0}$ & 0.567 \\
& Caucasian & 0.941 & $<0.001$ & Fixed & 0.874 & $0.670-1.141$ & 0.323 & 0.602 \\
& All & $<0.001$ & 72.535 & Random & 1.364 & $0.888-2.093$ & 0.156 & 0.624 \\
D/D versus I/D + I/I & Asian & 0.203 & 3.835 & Fixed & 3.326 & $2.190-5.050$ & $<\mathbf{0 . 0 0 1}$ & 0.347 \\
& Caucasian & 0.229 & 25.041 & Random & 0.955 & $0.710-1.286$ & 0.764 & 0.278 \\
\hline
\end{tabular}

COPD: chronic obstructive pulmonary disease; ACE: angiotensin-converting enzyme; OR: odds ratio; CI: confidence interval; I/I: insertion/insertion genotype; $\mathrm{I} / \mathrm{D}$ : insertion/deletion genotype; D/D: deletion/deletion genotype.

the dominant model (D/D genotype $+\mathrm{I} / \mathrm{D}$ genotype versus $\mathrm{I} / \mathrm{I}$ genotype), OR was $1.500(95 \% \mathrm{CI}=1.018-2.210, p=0.040)$ and $p$ value and $I^{2}$ for heterogeneity were 0.412 and $<0.001$, respectively, in the fixed model. For the recessive model (D/D genotype versus I/D genotype $+\mathrm{I} / \mathrm{I}$ genotype), OR was 3.326 (95\% CI $=2.190-5.050, p<0.001)$ and $p$ value and $I^{2}$ for heterogeneity were 0.203 and 3.835 , respectively, in the fixed model. OR for the homozygote comparison (D/D genotype versus I/I genotype) was $3.126(95 \% \mathrm{CI}=1.919-5.093, p<$ $0.001)$ and $p$ value and $I^{2}$ for heterogeneity were 0.358 and 6.964, respectively, in the fixed model. In the allele model, $\mathrm{D}$ allele of the ACE gene showed a significant association with the risk of COPD $(\mathrm{OR}=1.887,95 \% \mathrm{CI}=1.468-2.427$, $p<0.001$ ).

The present results obtained from these genetic models suggested that insertion/deletion polymorphism of the ACE gene was significantly associated with a strong risk of COPD in the Asian population but not in the Caucasian population. Figures 1(a)-1(e) show the meta-analysis results for the codominant, dominant, and recessive models and the allele model in the Asian population, respectively.

To identify publication bias in the meta-analysis, funnel plots for all comparison models were generated to detect the presence of publication biases. The shapes of all of the funnels 


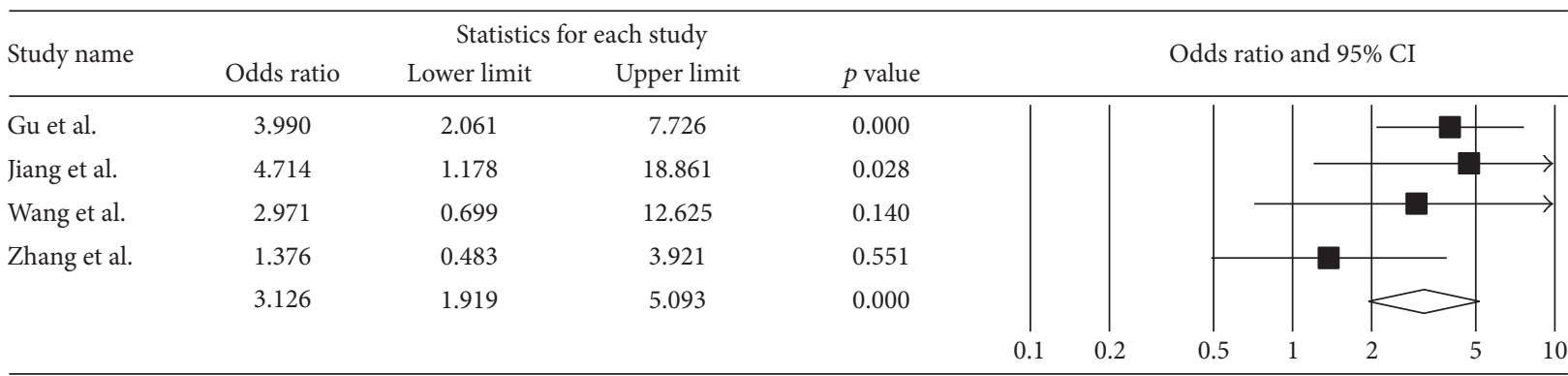

(a)

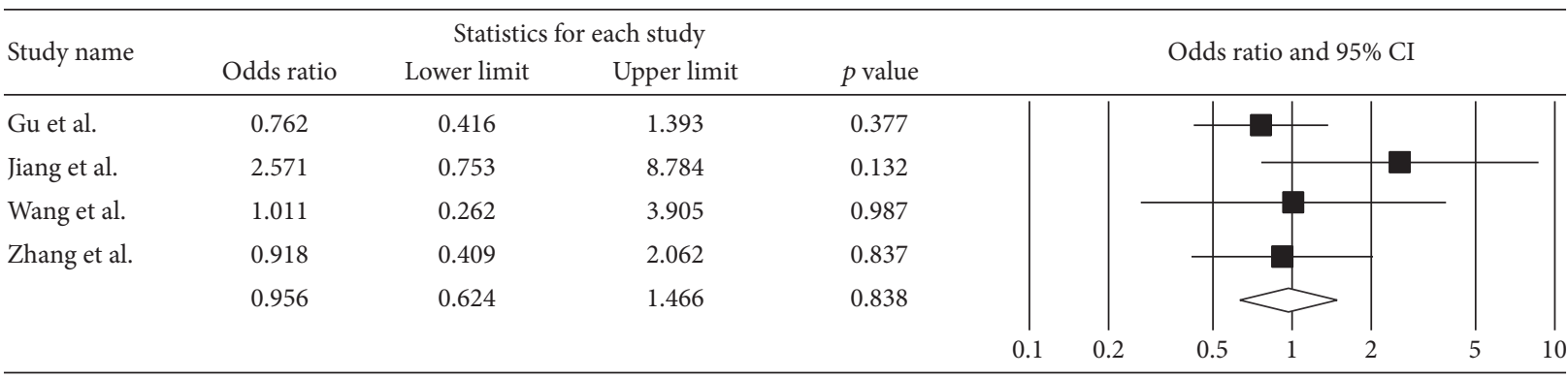

(b)

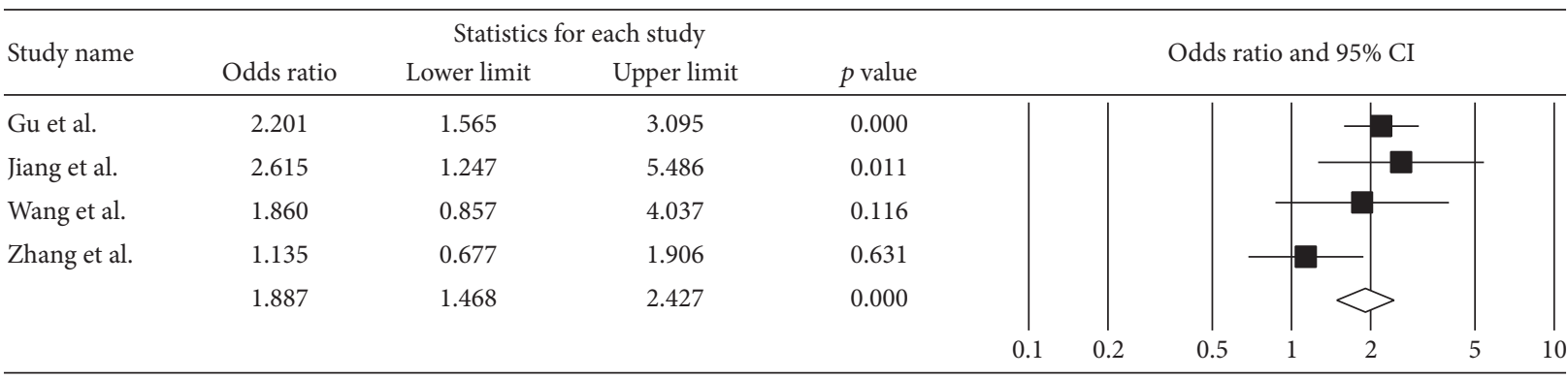

(c)

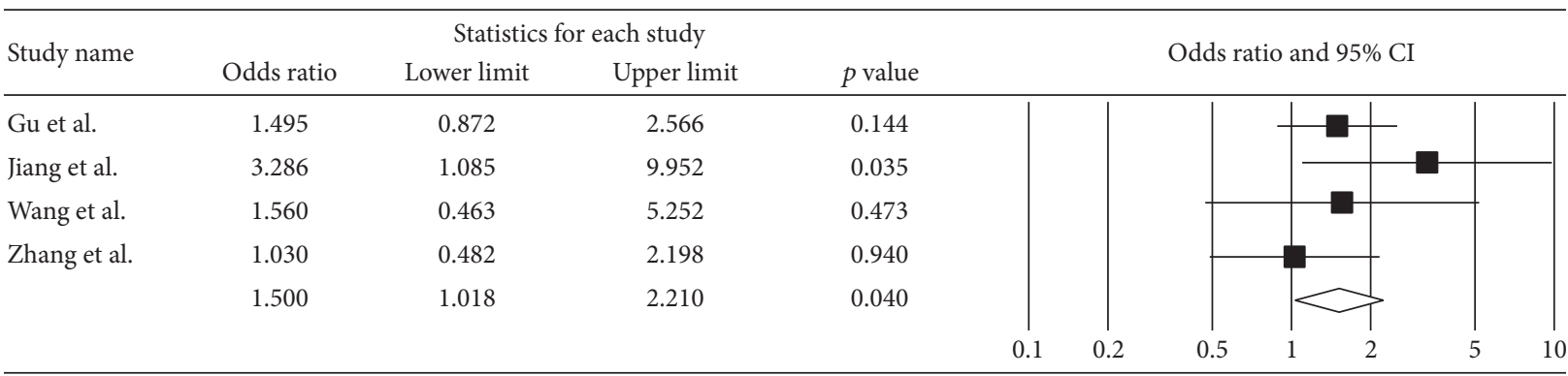

(d)

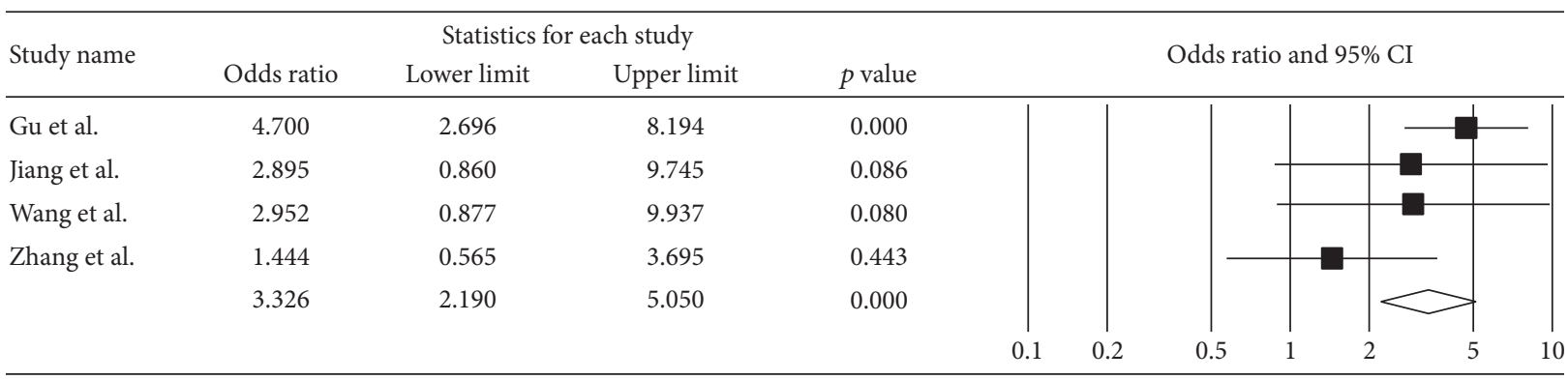

(e)

FIGURE 1: Odds ratio and 95\% CI of individual and pooled data for the ACE insertion/deletion polymorphism and susceptibility to COPD in Asian. (a) D/D genotype versus I/I genotype, (b) I/D genotype versus I/I genotype, (c) D allele versus I allele, (d) D/D genotype + I/D genotype versus I/I genotype, and (e) D/D genotype versus I/D genotype + I/I genotype. 
were symmetrical. We also evaluated publication bias using Egger's regression. There was no publication bias $(p>0.05$, Table 2).

\section{Discussion}

A high amount of ACE is located in the lung capillaries [36] and it is involved in catalyzing the conversion of angiotensin I and converts it to an active peptide, angiotensin II. Angiotensin II functions as a strong vasoconstrictor agent and controls pulmonary vascular tone [37]. ACE insertion/deletion polymorphism is associated with serum ACE levels [20] and D allele is related to increased formation of angiotensin II [38]. Thus, ACE insertion/deletion polymorphism has been reported to have an association with various diseases. The relationships between $A C E$ polymorphism and autism [39], the pathogenesis of pulmonary hypertension [40], psoriasis [41], chronic kidney failure [42], and so on have been reported. As mentioned above, the deletion polymorphism, the $\mathrm{D}$ allele, of the $A C E$ gene is associated with a higher ACE activity [20], and an elevation of the ACE activity was observed in COPD patients [43]. Therefore, the associations between $A C E$ polymorphism and COPD have been investigated in many previous studies [13-16, 26, 28, 31, $44,45]$. However, the results of previous studies regarding the association between $A C E$ polymorphism and COPD were conflicting and contradictory.

Previous two meta-analysis studies that assessed the relationship between ACE polymorphism and COPD risk failed to verify the link in the Caucasian population, but they found an association in the Asian population $[46,47]$. Our metaanalysis results were in agreement with the previous results. A total of 977 COPD cases and 1,092 controls were included in the present study. We could not identify any statistically significant association between ACE polymorphism and COPD risk. But when we performed a meta-analysis in the subgroup based on ethnicity, we found a strong association between $A C E$ polymorphism and COPD risk in the Asian population $(p<0.001)$ but not in the Caucasian population. A previous study examined the ratio of the frequencies of ACE II, ID, and DD genotypes among various ethnicities. The study showed that the ratio of the frequencies of $A C E$ II, ID, and DD genotypes was $1: 2: 1$ in the Europeans; there was a tendency towards a higher D allele frequency in the Nigerians, and there was a tendency towards a higher I allele frequency in the Samoans and the Yanomami Indians [48]. Although our study did not include Nigerians, Samoans, or Yanomami Indians, allele distribution between the Asian and Caucasian populations was different (all studies in the Asian population showed a higher I allele frequency). This might have led to a difference in the results between the two ethnicities.

According to GBD study, age-standardized death rates for COPD are higher in low-income countries such as South Asian and Sub-Saharan African countries [49]. But, the rate is similar in developed countries. In Korea, medical costs per person were US\$ 2,803 $\pm 3,865$ in 2009 and the total cost of COPD-related medications increased by $33.1 \%$ over 5 years [50]. Also, patients with high grade COPD impose three times higher economic burden $(\$ 3,744$ versus $\$ 1,183)$ on the health care system in Korea [51]. In Singapore, the mean total cost was approximately $\$ 9.9$ million per year and $42 \%$ of the total cost burden was incurred for the medical management of COPD [52]. Thus, the importance of prediction and early diagnosis of COPD, both clinically and economically, has increased.

In the present study, we collected previous studies that assessed the relationship between COPD risk and ACE polymorphism, but our study has some limitations. Our results showed the association between $A C E$ polymorphism and COPD risk. However, we could not investigate various ethnic distributions because most of the studies included only the Caucasian and Asian populations. Also, environmental factors are key factors in COPD, but we could not consider the environmental factors in this meta-analysis. As mentioned above, our results showed no evidence of publication bias, but some results were influenced by the included articles.

Despite some limitations, our results showed a statistically significant difference in the allele and genotype distribution in the Asian population. If more results in various populations are obtained in further studies, the relationship between $A C E$ polymorphism and the development of COPD can be clarified.

\section{Competing Interests}

The authors declare no competing interests regarding the publication of this article.

\section{Authors' Contributions}

Sang Wook Kang and Su Kang Kim equally contributed to this work.

\section{Acknowledgments}

This study was supported by a grant of the Traditional Korean Medicine R\&D Project, Ministry of Health \& Welfare, Republic of Korea (HI15C0171).

\section{References}

[1] A. Di Stefano, G. Caramori, F. L. M. Ricciardolo, A. Capelli, I. M. Adcock, and C. F. Donner, "Cellular and molecular mechanisms in chronic obstructive pulmonary disease: an overview," Clinical and Experimental Allergy, vol. 34, no. 8, pp. 1156-1167, 2004.

[2] J. B. Soriano and B. Lamprecht, "Chronic obstructive pulmonary disease: a worldwide problem," The Medical Clinics of North America, vol. 96, no. 4, pp. 671-680, 2012.

[3] J. B. Soriano and R. Rodríguez-Roisin, "Chronic obstructive pulmonary disease overview: epidemiology, risk factors, and clinical presentation," Proceedings of the American Thoracic Society, vol. 8, no. 4, pp. 363-367, 2011.

[4] C. J. Murray, A. D. Lopez, R. Black et al., "Global burden of disease 2005: call for collaborators," The Lancet, vol. 370, no. 9582, pp. 109-110, 2007.

[5] D. E. Grigoriadis, D. Pearsall, and E. B. De Souza, "Effects of chronic antidepressant and benzodiazepine treatment on 
corticotropin-releasing-factor receptors in rat brain and pituitary," Neuropsychopharmacology, vol. 2, no. 1, pp. 53-60, 1989.

[6] M. D. Eisner, N. Anthonisen, D. Coultas et al., "An official American Thoracic Society public policy statement: novel risk factors and the global burden of chronic obstructive pulmonary disease," American Journal of Respiratory and Critical Care Medicine, vol. 182, no. 5, pp. 693-718, 2010.

[7] P. D. Blanc, A. M. B. Menezes, E. Plana et al., "Occupational exposures and COPD: an ecological analysis of international data," The European Respiratory Journal, vol. 33, no. 2, pp. 298304, 2009.

[8] M. Ezzati, S. V. Hoorn, A. Rodgers, A. D. Lopez, C. D. Mathers, and C. J. L. Murray, "Estimates of global and regional potential health gains from reducing multiple major risk factors," The Lancet, vol. 362, no. 9380, pp. 271-280, 2003.

[9] L. Joos, P. D. Paré, and A. J. Sandford, "Genetic risk factors for chronic obstructive pulmonary disease," Swiss Medical Weekly, vol. 132, no. 3-4, pp. 27-37, 2002.

[10] C. M. Yun and X. Y. Sang, "Role of proteinase-activated receptor-1 gene polymorphisms in susceptibility to chronic obstructive pulmonary disease," Genetics and Molecular Research, vol. 14, no. 4, pp. 13215-13220, 2015.

[11] E. S. Essa and R. A. El Wahsh, "Association between Plasminogen activator inhibitor-1-675 4G/5G insertion/deletion polymorphism and chronic obstructive pulmonary disease," COPD, 2016.

[12] W. Wang, P. Li, Y. Chen, and J. Yang, "Association between $\beta 2$-adrenergic receptor-16Arg/Gly gene polymorphism and chronic obstructive pulmonary disease risk: systematic review and meta-analysis," Iranian Journal of Public Health, vol. 43, no. 7, pp. 877-888, 2014.

[13] C. Ayada, Ü. Toru, O. Genç et al., "Evaluation of whether the ACE gene I/D polymorphism constitutes a risk factor for chronic obstructive pulmonary disease in the Turkish population," Genetics and Molecular Research, vol. 13, no. 4, pp. 10427-10433, 2014.

[14] S. Simsek, S. Tekes, D. Oral et al., “The insertion/deletion polymorphism in the ACE gene and chronic obstructive pulmonary disease," Genetics and Molecular Research, vol. 12, no. 2, pp. 1392-1398, 2013.

[15] X. Busquets, N. G. MacFarlane, D. Heine-Suñer et al., "Angiotensin-converting-enzyme gene polymorphisms, smoking and chronic obstructive pulmonary disease," International Journal of Chronic Obstructive Pulmonary Disease, vol. 2, no. 3, pp. 329-334, 2007.

[16] A. Ahsan, R. Ram, M. A. Baig, and M. A. Q. Pasha, "ACE I allele and eNOS G allele crosstalk may have a role in chronic obstructive pulmonary disease," Clinical Biochemistry, vol. 37, no. 11, pp. 1037-1040, 2004.

[17] V. Pradhan, E. H. Kemp, M. Nadkar et al., "Association between the angiotensin-converting enzyme gene insertion/deletion polymorphism and susceptibility to systemic lupus erythematosus in an Indian population," Scandinavian Journal of Rheumatology, vol. 44, no. 5, pp. 425-427, 2015.

[18] R. Shanmuganathan, R. Kumaresan, and P. Giri, "Prevalence of angiotensin converting enzyme (ACE) gene insertion/deletion polymorphism in South Indian population with hypertension and chronic kidney disease," Journal of Postgraduate Medicine, vol. 61, no. 4, pp. 230-234, 2015.

[19] D. N. Parchwani, M. G. Kesari, D. D. Patel, and D. J. Patel, "Influence of genetic variability at the ACE locus in intron 16 on Diabetic Nephropathy in T1DM patients," Indian Journal of Physiology and Pharmacology, vol. 58, no. 4, pp. 327-337, 2014.

[20] B. Rigat, C. Hubert, F. Alhenc-Gelas, F. Cambien, P. Corvol, and F. Soubrier, "An insertion/deletion polymorphism in the angiotensin I-converting enzyme gene accounting for half the variance of serum enzyme levels," Journal of Clinical Investigation, vol. 86, no. 4, pp. 1343-1346, 1990.

[21] E. Barát, G. Böszörményi-Nagy, and L. A. Debreczeni, "Serum angiotensin converting enzyme values in chronic obstructive pulmonary disease," Acta Physiologica Hungarica, vol. 70, no. 2-3, pp. 337-342, 1987.

[22] B. Al'tshuler, A. P. Roitman, V. V. Dolgov, G. A. Iarovaia, E. A. Neshkova, and T. A. Fedorova, "The change in the activity of angiotensin converting enzyme in patients with pneumonia and chronic obstructive pulmonary diseases," Klinicheskaia Laboratornaia Diagnostika, no. 1, pp. 10-15, 2002.

[23] K. J. Curtis, V. M. Meyrick, B. Mehta et al., "Angiotensinconverting enzyme inhibition as an adjunct to pulmonary rehabilitation in COPD," American Journal of Respiratory and Critical Care Medicine, 2016.

[24] H. Seok, S. K. Kim, K. H. Yoo, B. Lee, Y. O. Kim, and J. Chung, "Association of BID SNPs (rs8190315 and rs2072392) and clinical features of benign prostate hyperplasia in Korean population," Journal of Exercise Rehabilitation, vol. 10, no. 6, pp. 383-388, 2014.

[25] H. K. Park and S. K. Kim, "Promoter polymorphisms of NDUFA4 gene were associated with prostate enlargement of benign prostatic hyperplasia," Molecular and Cellular Toxicology, vol. 11, no. 4, pp. 401-406, 2015.

[26] S. S. Ulasli, F. O. Eyuboglu, H. Verdi, and F. B. Atac, "Associations between endothelial nitric oxide synthase A/B, angiotensin converting enzyme I/D and serotonin transporter $\mathrm{L} / \mathrm{S}$ gene polymorphisms with pulmonary hypertension in COPD patients," Molecular Biology Reports, vol. 40, no. 10, pp. 5625-5633, 2013.

[27] S. Pabst, B. Theis, A. Gillissen et al., "Angiotensin-converting enzyme I/D polymorphism in chronic obstructive pulmonary disease," European Journal of Medical Research, vol. 14, no. 4, pp. 177-181, 2009.

[28] X. Zhang, C. Wang, H. Dai, Y. Lin, and J. Zhang, "Association between angiotensin-converting enzyme gene polymorphisms and exercise performance in patients with COPD," Respirology, vol. 13, no. 5, pp. 683-688, 2008.

[29] N. S. Hopkinson, K. W. Li, A. Kehoe et al., "Vitamin D receptor genotypes influence quadriceps strength in chronic obstructive pulmonary disease," The American Journal of Clinical Nutrition, vol. 87, no. 2, pp. 385-390, 2008.

[30] R. Tkáčová, P. Joppa, B. Stančák, J. Šalagovič, S. Mišíková, and I. Kalina, "The link between angiotensin-converting enzyme genotype and pulmonary artery pressure in patients with COPD," Wiener Klinische Wochenschrift, vol. 117, no. 5-6, pp. 210-214, 2005.

[31] P. Yildiz, H. Oflaz, N. Cine, N. Erginel-Ünaltuna, F. Erzengin, and V. Yilmaz, "Gene polymorphisms of endothelial nitric oxide synthase enzyme associated with pulmonary hypertension in patients with COPD," Respiratory Medicine, vol. 97, no. 12, pp. 1282-1288, 2003.

[32] R. J. van Suylen, E. F. Wouters, H. J. Pennings et al., "The DD genotype of the angiotensin converting enzyme gene is negatively associated with right ventricular hypertrophy in male patients with chronic obstructive pulmonary disease," American 
Journal of Respiratory and Critical Care Medicine, vol. 159, no. 6, pp. 1791-1795, 1999.

[33] C. Jiang and N. Zhang, "Angiotensin-converting enzyme I/D polymorphism in patients with chronic obstructive pulmonary disease and pneumocardial disease," Guo Wai Yi Xue, vol. 23, pp. 248-249, 2004 (Chinese).

[34] H. Gu, H. Zhang, and L. Yang, "Relationships between polymorphisms of gene coding angiotensin converting enzyme and susceptibility to chronic obstructive pulmonary disease," Ji Chu Yi Xue Yu Lin Chuang, vol. 23, pp. 174-177, 2003.

[35] H. W. Wang, Z. S. Nie, Y. Z. Duan et al., "Association between polymorphism in ACE gene with lung cancer and COPD patients," Hai Jun Zong Yi Yuan Xue Bao, vol. 13, pp. 203-206, 2000.

[36] C. Orte, J. M. Polak, S. G. Haworth, M. H. Yacoub, and N. W. Morrell, "Expression of pulmonary vascular angiotensinconverting enzyme in primary and secondary plexiform pulmonary hypertension," Journal of Pathology, vol. 192, no. 3, pp. 379-384, 2000.

[37] V. J. De Beer, H. J. D. De Graaff, M. Hoekstra, D. J. Duncker, and D. Merkus, "Integrated control of pulmonary vascular tone by endothelin and angiotensin II in exercising swine depends on gender," American Journal of Physiology-Heart and Circulatory Physiology, vol. 298, no. 6, pp. H1976-H1985, 2010.

[38] S. Ueda, H. L. Elliott, J. J. Morton, and J. M. C. Connell, "Enhanced pressor response to angiotensin I in normotensive men with the deletion genotype (DD) for angiotensinconverting enzyme," Hypertension, vol. 25, no. 6, pp. 1266-1269, 1995.

[39] N. Firouzabadi, N. Ghazanfari, A. Alavi Shoushtari et al., "Genetic variants of angiotensin-converting enzyme are linked to autism: a case-control study," PLoS ONE, vol. 11, no. 4, Article ID e0153667, 2016.

[40] H. Kanazawa, T. Okamoto, K. Hirata, and J. Yoshikawa, "Deletion polymorphisms in the angiotensin converting enzyme gene are associated with pulmonary hypertension evoked by exercise challenge in patients with chronic obstructive pulmonary disease," American Journal of Respiratory and Critical Care Medicine, vol. 162, no. 4, pp. 1235-1238, 2000.

[41] S. Munir, S. B. Rahman, S. Rehman et al., "The angiotensinconverting enzyme gene insertion polymorphism: a higher risk for psoriasis in male patients," The British Journal of Dermatology, vol. 175, no. 4, pp. 824-826, 2016.

[42] T. Sarkar, N. P. Singh, P. Kar et al., "Does angiotensin-converting enzyme-1 (ACE-1) gene polymorphism lead to chronic kidney disease among hypertensive patients?" Renal Failure, vol. 38, no. 5, pp. 765-769, 2016.

[43] E. A. W. Brice, W. Friedlander, E. D. Bateman, and R. E. Kirsch, "Serum angiotensin-converting enzyme activity, concentration, and specific activity in granulomatous interstitial lung disease, tuberculosis, and COPD," Chest, vol. 107, no. 3, pp. 706-710, 1995.

[44] N. A. Kuzubova, A. B. Chukhlovin, E. B. Morozova, A. A. Totolian, and O. N. Titova, "Common intronic D variant of ACE gene is associated with endothelial dysfunction in COPD," Respiratory Medicine, vol. 107, no. 8, pp. 1217-1221, 2013.

[45] J. Lee, B. G. Nordestgaard, and M. Dahl, "Elevated ACE activity is not associated with asthma, COPD, and COPD co-morbidity," Respiratory Medicine, vol. 103, no. 9, pp. 1286-1292, 2009.

[46] W. Li, F. Lan, F. Yan, and H. Shen, "Angiotensin-converting enzyme I/D polymorphism is associated with COPD risk in
Asian population: evidence from a meta-analysis," Journal of Chronic Obstructive Pulmonary Disease, vol. 10, no. 1, pp. 35-39, 2013.

[47] X. Li, N. Wei, Z. Wu et al., "The D/I polymorphism in the angiotensin-converting enzyme gene and chronic obstructive pulmonary disease risk: a meta-analysis," Journal of Chronic Obstructive Pulmonary Disease, vol. 9, no. 5, pp. 485-491, 2012.

[48] J. Barley, A. Blackwood, N. D. Carter et al., "Angiotensin converting enzyme insertion/deletion polymorphism: ASSOCIATION with ethnic origin," Journal of Hypertension, vol. 12, no. 8, pp. 955-957, 1994.

[49] J. L. Lõpez-Campos, W. Tan, and J. B. Soriano, "Global burden of COPD," Respirology, vol. 21, no. 1, pp. 14-23, 2016.

[50] C. Kim, K. H. Yoo, C. K. Rhee et al., "Health care use and economic burden of patients with diagnosed chronic obstructive pulmonary disease in Korea," The International Journal of Tuberculosis and Lung Disease, vol. 18, no. 6, pp. 737-743, 2014.

[51] J. H. Kim, C. K. Rhee, K. H. Yoo et al., "The health care burden of high grade chronic obstructive pulmonary disease in Korea: analysis of the Korean Health Insurance Review and Assessment Service data," International Journal of COPD, vol. 8, pp. 561-568, 2013.

[52] W.-S. K. Teo, W.-S. Tan, W.-F. Chong et al., "Economic burden of chronic obstructive pulmonary disease," Respirology, vol. 17, no. 1, pp. 120-126, 2012. 


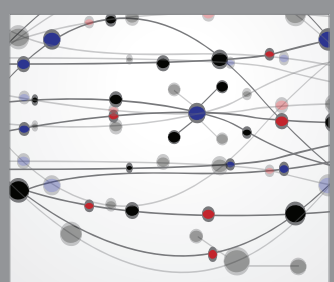

The Scientific World Journal
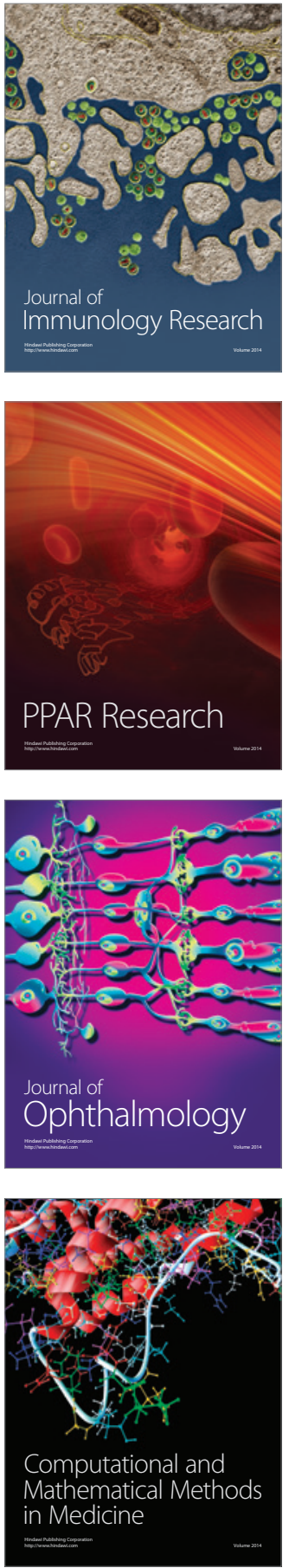

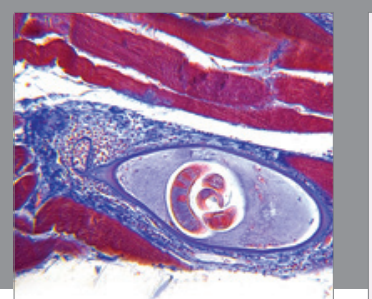

Gastroenterology Research and Practice

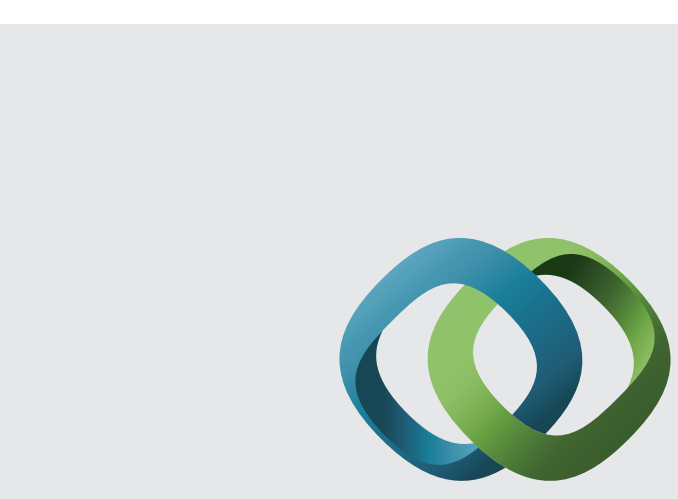

\section{Hindawi}

Submit your manuscripts at

http://www.hindawi.com
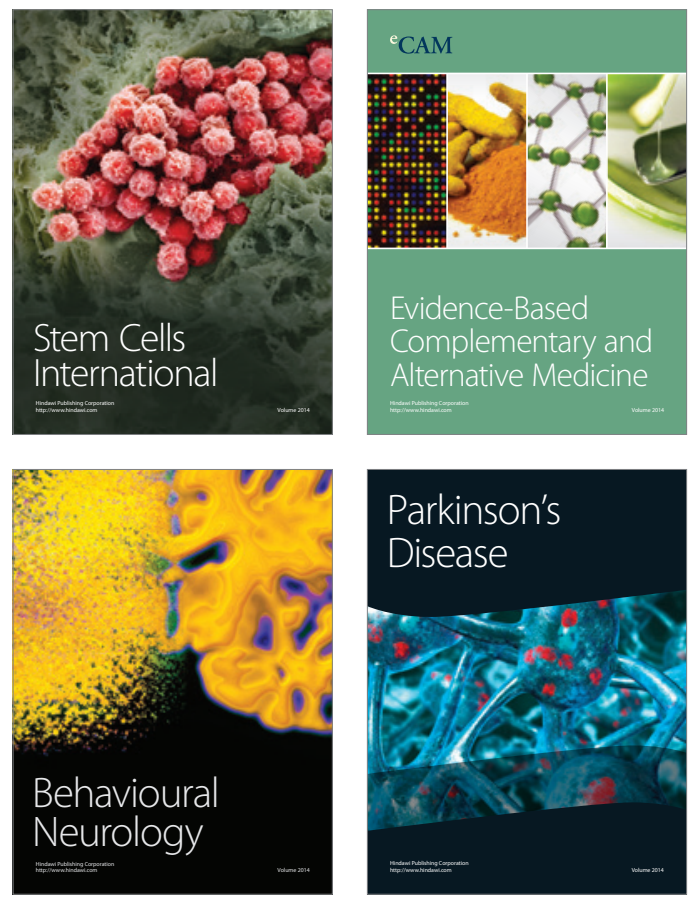
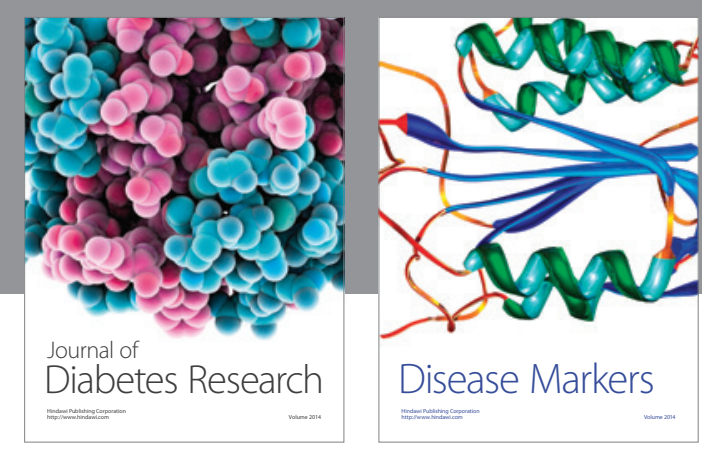

Disease Markers
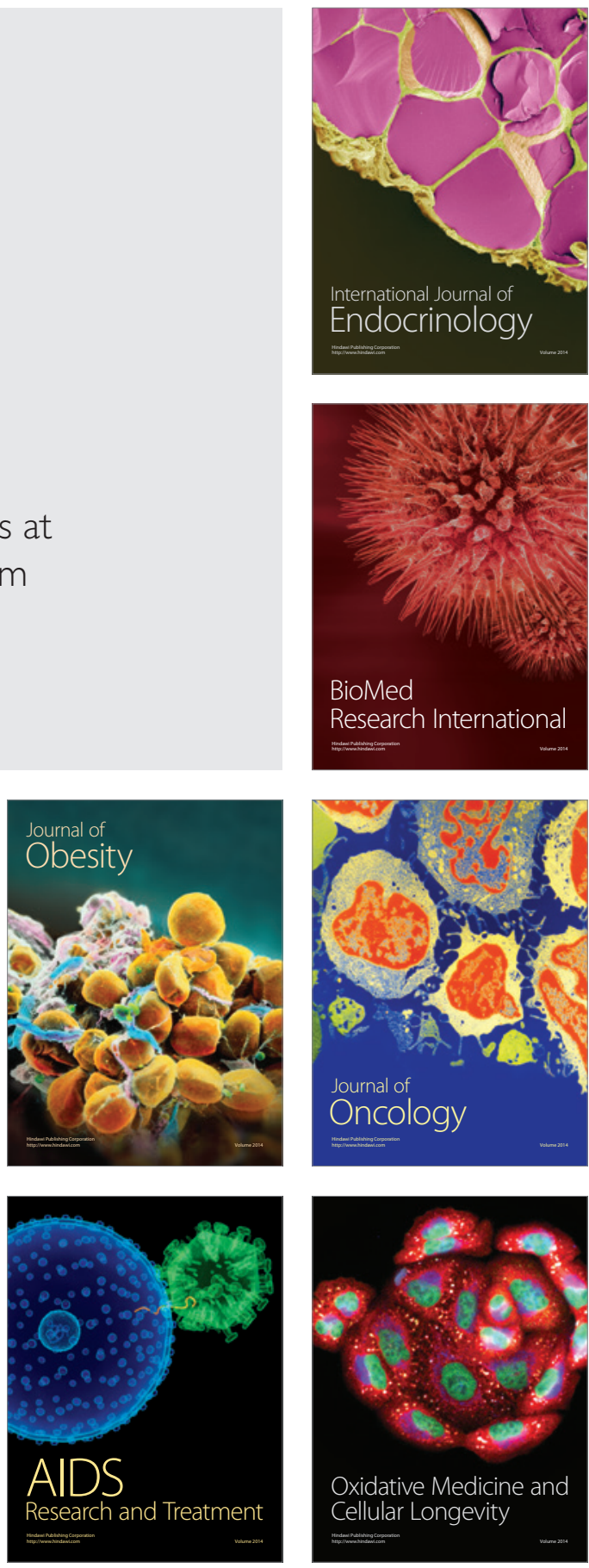